\title{
Effect of somatometric parameters on the prevalence and severity of varicocele: a systematic review and meta-analysis
}

\author{
Runqing $\mathrm{Li}^{1}$, Junjie Liu${ }^{2}$, Yushan $\mathrm{Li}^{2^{*}}$ and Quanxian Wang ${ }^{2}$
}

\begin{abstract}
Background: Published studies have shown contradictory results regarding the relationship between somatometric parameters and varicoceles. We performed a systematic review and meta-analysis to investigate the possible effects of age, height, weight, and body mass index (BMI) on the presence and severity of varicoceles.

Methods: Databases including EMBASE, MEDLINE, PubMed, Cochrane Library, China National Knowledge Infrastructure (CNKI), Web of Science, and Google Scholar were systematically searched to identify relevant articles published up to March 2020. Two researchers independently identified eligible articles and extracted data. Cochran's Q statistic and I ${ }^{2}$ statistics were used to assess heterogeneity. Meta-analysis was performed using StataSE 12.0 software (StataCorp LP, USA). Random-effects models were used to obtain the weighted mean differences (WMDs) and 95\% confidence intervals (Cls). Publication bias was assessed using Begg's funnel plot and Egger's regression test.
\end{abstract}

Results: The search strategy produced 272 articles, of which 18 articles were eligible according to the inclusion/ exclusion criteria. A total of 56,325 patients with varicocele and 1,334,694 patients without varicocele were included in the meta-analysis to evaluate the effect of somatometric parameters on the presence and severity of varicocele. The overall results demonstrated that the presence of varicoceles was significantly associated with height (WMD $=$ $1.41,95 \% \mathrm{Cl}=1.07$ to $1.74, P<0.001)$ and inversely correlated with $\mathrm{BMI}(\mathrm{WMD}=-1.35,95 \% \mathrm{Cl}=-1.67$ to $-1.03, P<$ $0.001)$ but not with age $(\mathrm{WMD}=-0.93,95 \% \mathrm{Cl}=-2.19$ to $0.33, P=0.149)$ or weight $(\mathrm{WMD}=0.24,95 \% \mathrm{Cl}=-2.24$ to $2.72, P=0.850)$. The severity of varicocele was inversely correlated with increased BMI but not with age.

Conclusion: The presence of varicoceles was significantly associated with height and inversely correlated with BMI. Keywords: Meta-analysis, Varicocele, Age, Height, Weight, Body mass index

\footnotetext{
* Correspondence: liyushanrun@126.com

${ }^{2}$ Henan Human Sperm Bank, The Third Affiliated Hospital of Zhengzhou University, No.7 Front Kangfu Street, Er'qi District, Zhengzhou 450052, People's Republic of China

Full list of author information is available at the end of the article
}

(c) The Author(s). 2021 Open Access This article is licensed under a Creative Commons Attribution 4.0 International License, which permits use, sharing, adaptation, distribution and reproduction in any medium or format, as long as you give appropriate credit to the original author(s) and the source, provide a link to the Creative Commons licence, and indicate if changes were made. The images or other third party material in this article are included in the article's Creative Commons licence, unless indicated otherwise in a credit line to the material. If material is not included in the article's Creative Commons licence and your intended use is not permitted by statutory regulation or exceeds the permitted use, you will need to obtain permission directly from the copyright holder. To view a copy of this licence, visit http://creativecommons.org/licenses/by/4.0/ The Creative Commons Public Domain Dedication waiver (http://creativecommons.org/publicdomain/zero/1.0/) applies to the data made available in this article, unless otherwise stated in a credit line to the data. 


\section{Strengths and limitations of this study}

- This meta-analysis included 56,325 patients with varicocele and 1,334,694 patients without varicocele

- The sample size was large enough to draw a reliable conclusion.

- Stratified analyses by study design and ethnicity were also performed in this meta-analysis

- We also investigated the effect of age and BMI on the severity of varicocele.

\section{Introduction}

Varicocele, an abnormal dilation of the pampiniform venous plexus in the scrotum, is the most common surgically correctable cause of male infertility [1-4]. The prevalence of varicocele is $15-20 \%$ in the general population, $21-41 \%$ in men with primary infertility, and $75-$ $81 \%$ in men with secondary infertility $[1,3,5-8]$. The exact mechanism of varicocele development has not been fully clarified. According to existing theories, varicocele is considered to be related to various factors resulting in abnormal dilation of the pampiniform venous plexus and venous drainage [7].

Previous studies have investigated the association between somatometric parameters and the prevalence and severity of varicocele. However, there are contradictory data regarding the relationship between somatometric parameters and the prevalence and severity of varicocele. Some studies have suggested that the prevalence of varicocele is positively associated with age [9], height [3, 8$15]$, weight $[10,11,14]$ and negatively correlated with BMI [3, 7-10, 15-20]. Other studies have suggested that the prevalence of varicocele is negatively associated with age [3] and weight [12, 15] or that the prevalence of varicocele is not associated with age $[13,18,21]$, weight [21], height [13, 21, 22], or BMI [11, 13, 21].

There are reports that the severity of varicoceles is inversely correlated with age $[20]$ and BMI $[18,19]$ or that the severity of varicoceles increases with height [12]. Other studies have reported that the severity of varicoceles is not associated with age [21], weight [12, 21], height [21], and BMI [12, 21]. In addition, Bake et al. [23] reported that patients with grade III varicocele had a lower BMI than those with grade I and II varicocele, but this was not significant.

The objective of this systematic review and metaanalysis was to evaluate the effect of age, height, weight, and BMI on the prevalence and severity of varicocele.

\section{Materials and methods}

\section{Search strategy}

The study was conducted according to the Preferred Reporting Items for Systematic Reviews and MetaAnalyses (PRISMA) guidelines [24]. Databases including
EMBASE, MEDLINE, PubMed, Cochrane Library, China National Knowledge Infrastructure (CNKI), Web of Science, and Google Scholar were systematically searched to identify relevant articles published up to March 2020. We searched the literature using the following terms: "varicocele", "varicoceles", "varicocelegrade", "body mass index", "BMI", "age", "height", "weight", and "somatometric parameters". Patient informed consent and ethical approval were not required since this study is a meta-analysis based on published articles.

\section{Inclusion and exclusion criteria}

Observational and experimental studies were included in this systematic review and meta-analysis if they met the following criteria: (1) the topic is varicocele; (2) observational studies published as original studies to assess the effect of age, height, weight, and BMI on the prevalence and/or severity of varicocele; (3) directly measured height and weight; (4) the data for age, height, weight or BMI should be reported as the means with standard deviations (SDs); and (5) sufficient data to calculate the weighted mean differences (WMDs). The exclusion criteria were as follows: (1) abstracts, reviews, letters, and editorials; (2) case-only studies; (3) unpublished or inaccessible full articles; and (4) duplicate publications. Grades of varicocele were determined according to physical examination and sonographic parameters. Varicocele was graded as follows: grade I, palpable only with the Valsalva manoeuvre; grade II, palpable without the Valsalva manoeuvre but not visible; and grade III, visible from a distance without palpation [21].

\section{Study selection}

Two authors (R.L. and J.L.) independently reviewed all articles based on the predetermined inclusion/exclusion criteria, and the results were cross-checked. Relevant articles were initially identified by reviewing the titles and abstracts. When appropriateness could not be determined, the full-text of each remaining article was retrieved and assessed to determine whether the inclusion/ exclusion criteria were satisfied. If any disagreements occurred, a third author (Y.L.) reviewed the article and made a final decision after careful discussion.

\section{Data extraction}

Two authors (R.L. and J.L.) independently extracted data from the eligible studies, and the final results were cross-checked. If any disagreements occurred, a third author (Y.L.) reviewed the article and made a final decision after careful discussion. For each eligible study, the following information was collected: author name, year of publication, type of study design, country of origin, ethnicity group, sample size, and age. 


\section{Quality assessment of the included studies}

The quality of the included case-control studies was assessed using the Newcastle-Ottawa Scale (NOS) [25]. The quality of the included cross-sectional studies was assessed using the Agency for Healthcare Research and Quality (AHRQ) criteria [26].

\section{Statistical analysis}

Meta-analysis was performed using Stata SE 12.0 software (StataCorp LP, USA). Cochran's Q statistic and $\mathrm{I}^{2}$ statistics were used to assess heterogeneity $(P<0.10$ and/or $I^{2}>50 \%$ indicated significant heterogeneity). Random-effects models were used to obtain the pooled WMDs and 95\% confidence intervals (CIs). Sensitivity analysis was performed by excluding each study to examine the influence of individual studies on the pooled results. Possible publication bias was assessed using Begg's funnel plot and Egger's regression test. $P<$ 0.05 was considered statistically significant.

\section{Results}

\section{Study selection}

Details of the search and screening process are graphically described in Fig. 1. Based on our search strategy, 272 studies were identified. After removing 74 duplicate studies, we reviewed the titles and abstracts of 198 studies. After reading the titles and abstracts, 26 studies were included. After reading the full text of the remaining studies, 8 studies were excluded for various reasons. Finally, 18 studies were eligible for the meta-analysis, which involved 1,391,360 subjects (56,390 patients with varicocele and 1,334,970 patients without varicocele).

\section{Study characteristics and quality}

The main characteristics of the included studies are summarized in Table 1. Overall, these included studies were published between 2006 and 2018. Among the 18 studies, 11 were case-control studies, and 7 were crosssectional studies.
Records identified through PubMed,
MEDLINE, EMBASE, Cochrane Library,
CNKI, Web of Science, and Google Scholar $(\mathrm{n}=260)$
Records identified from all references screened $(\mathrm{n}=12)$

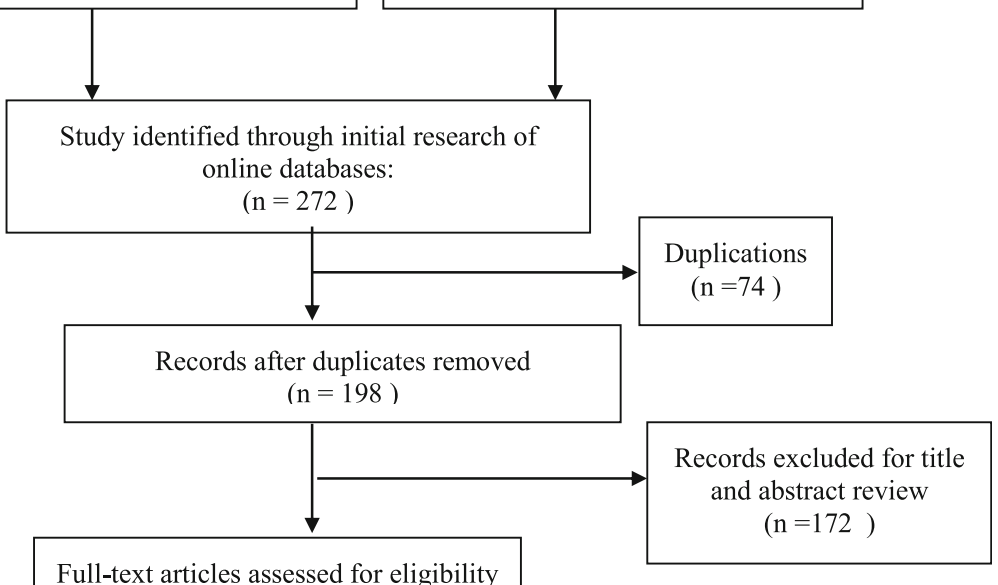

$$
(\mathrm{n}=26)
$$

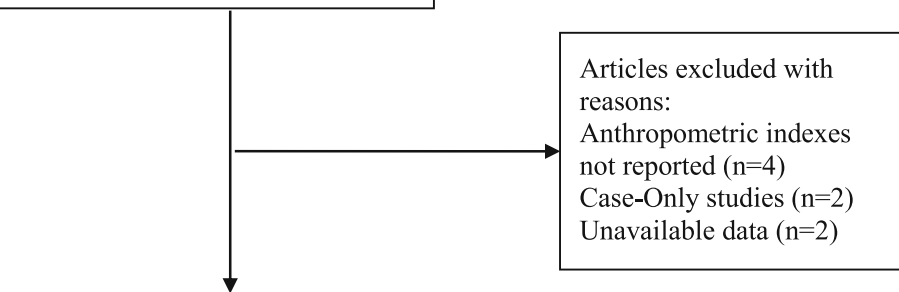

Finally, articles included in our systematic review and meta-analysis $(\mathrm{n}=18)$

Fig. 1 Flow chart of the identified, included, and excluded studies 
Table 1 Characteristics of participants in included studies

\begin{tabular}{|c|c|c|c|c|c|c|c|c|c|}
\hline \multirow[t]{2}{*}{ Study } & \multirow[t]{2}{*}{ Year } & \multirow[t]{2}{*}{ Study design } & \multirow[t]{2}{*}{ Ethnicity } & \multirow[t]{2}{*}{ Country } & \multicolumn{2}{|l|}{ Sample size } & \multirow{2}{*}{$\begin{array}{l}\text { Age } \\
\text { (years) }\end{array}$} & \multirow{2}{*}{$\begin{array}{l}\text { Included varicocele } \\
\text { patients }\end{array}$} & \multirow{2}{*}{$\begin{array}{l}\text { Quality } \\
\text { score }\end{array}$} \\
\hline & & & & & Varicocele & Non-varicocele & & & \\
\hline Handel et al. [16] & 2006 & Case-control & Caucasian & USA & 1093 & 2120 & NA & Left. right and bilateral & 8 \\
\hline Kilic et al. [13] & 2007 & Case-control & Caucasian & Turkey & 52 & 100 & $14-50$ & Left. right and bilateral & 7 \\
\hline Tsao et al. [19] & 2009 & Cross-sectional & Asian & China & 490 & 560 & $18-27$ & Left. right and bilateral & 8 \\
\hline Chen et al. [18] & 2010 & Case-control & Asian & China & 102 & 95 & $18-50$ & NA & 7 \\
\hline Farhan et al. [27] & 2010 & Case-control & Asian & Iraq & 206 & 206 & NA & Left. right and bilateral & 7 \\
\hline Chancwalters et al. [28] & 2012 & Case-control & Caucasian & USA & 330 & 749 & $18-40$ & Left. right and bilateral & 7 \\
\hline Soylemez et al. [21] & 2012 & Cross-sectional & Caucasian & Turkey & 498 & 1563 & $19-34$ & Left. right and bilateral & 7 \\
\hline Yigitler et al. [29] & 2012 & Cross-sectional & Caucasian & Turkey & 750 & 11,831 & $16-23$ & NA & 9 \\
\hline Özçelik et al. [30] & 2013 & Case-control & Caucasian & Turkey & 75 & 100 & $20-30$ & NA & 7 \\
\hline Rais et al. [31] & 2013 & Cross-sectional & Caucasian & Israel & 47,398 & $1,275,663$ & $17-18$ & NA & 9 \\
\hline Gokce et al. [8] & 2013 & Cross-sectional & Caucasian & Turkey & 587 & 1255 & $18-50$ & Right and bilateral & 8 \\
\hline Doğantekin et al. [32] & 2014 & Cross-sectional & Caucasian & T urkey & 210 & 390 & $21-38$ & Left. right and bilateral & 7 \\
\hline Bae et al. [33] & 2014 & Case-control & Asian & Korea & 211 & 102 & NA & NA & 7 \\
\hline Gorur et al. [34] & 2015 & Case-control & Caucasian & Turkey & 138 & 117 & $18-45$ & NA & 7 \\
\hline Liu et al. [35] & 2015 & Case-control & Asian & China & 73 & 104 & $18-50$ & NA & 7 \\
\hline Shafi et al. [36] & 2015 & Case-control & Asian & Iran & 153 & 250 & $18-40$ & Left. right and bilateral & 7 \\
\hline Liu et al. [7] & 2017 & Cross-sectional & Asian & China & 1911 & 37,648 & $21-49$ & Left. right and bilateral & 8 \\
\hline Pallotti et al. [3] & 2018 & Case-control & Caucasian & Italy & 2085 & 2080 & NA & Left. right and bilateral & 7 \\
\hline
\end{tabular}

\section{Age of varicocele and nonvaricocele patients}

Twelve studies investigated the relationship between age and the prevalence of varicocele. The overall results showed that there was no association between age and the prevalence of varicocele $(\mathrm{WMD}=-0.93,95 \% \mathrm{CI}=$ 2.19 to $0.33, P=0.149$ ) (Fig. 2a, Fig. $2 b$, and Table 2).

\section{Height of varicocele and nonvaricocele patients}

Ten studies investigated the relationship between height and the prevalence of varicocele. The overall results showed that patients with varicocele were significantly taller than patients without varicocele $(\mathrm{WMD}=1.41$, $95 \% \mathrm{CI}=1.07$ to $1.74, P<0.001$ ) (Fig. 2c, Fig. 2d, and Table 2). However, there was between-study heterogeneity that could not be ignored $\left(I^{2}=73.5 \%, P<0.001\right)$. Therefore, stratified analyses by study design and ethnicity were performed to explore the origin of significant heterogeneity. In the subgroup analysis of study design, patients with varicocele were significantly taller than patients without varicocele in the case-control studies (WMD $=2.19,95 \% \mathrm{CI}=0.91$ to $3.47, P=0.001$ ) and cross-sectional studies (WMD $=1.30,95 \% \mathrm{CI}=0.96$ to 1.63, $P<0.001$ ) (Fig. $2 c$ and Table 2). Similarly, the subgroup analysis by ethnicity indicated that patients with varicocele were significantly taller than patients without varicocele in the Asian population (WMD $=1.79,95 \%$ $\mathrm{CI}=0.75$ to $2.82, P=0.001)$ and Caucasian population
$(\mathrm{WMD}=1.37,95 \% \mathrm{CI}=0.94$ to $1.79, P<0.001)($ Fig. $2 \mathrm{~d}$ and Table 2).

\section{Weight of varicocele and nonvaricocele patients}

Seven studies investigated the relationship between weight and the prevalence of varicocele. The overall results showed that there was no association between weight and the prevalence of varicocele $(\mathrm{WMD}=0.24$, $95 \% \mathrm{CI}=-2.24$ to $2.72, P=0.850$ ) (Fig. 2e, Fig. 2f, and Table 2).

\section{BMI of varicocele and nonvaricocele patients}

Seventeen studies investigated the relationship between BMI and the prevalence of varicocele. The overall results showed that patients with varicocele had a significantly lower BMI than patients without varicocele (WMD = 1.35, 95\% CI: -1.67 to $-1.03, P<0.001$ ) (Fig. 2 g, Fig. $2 \mathrm{~h}$, and Table 2). However, there was between-study heterogeneity that could not be ignored $\left(I^{2}=96.5 \%, P<0.001\right)$. Therefore, stratified analyses by study design and ethnicity were performed to explore the origin of the significant heterogeneity. In the subgroup analysis of study design, patients with varicocele had a lower BMI than patients without varicocele in the case-control studies $(\mathrm{WMD}=-1.38,95 \% \mathrm{CI}=-2.06$ to $-0.70, P<0.001)$ and cross-sectional studies (WMD $=-1.29,95 \% \mathrm{CI}=-1.69$ to -0.89, $P<0.001$ ) (Fig. $2 \mathrm{~g}$ and Table 2). Similarly, the 

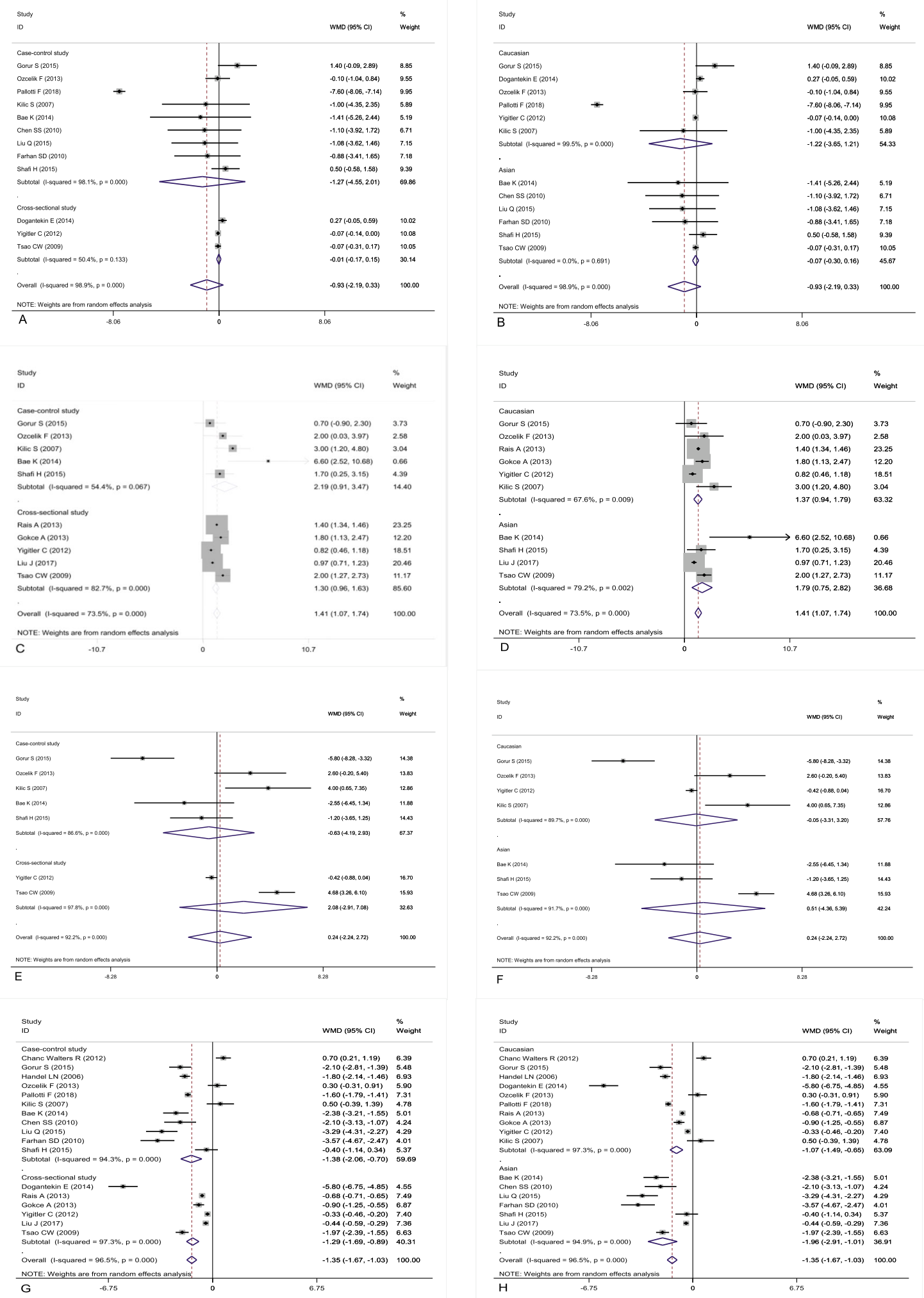

Fig. 2 (See legend on next page.) 
(See figure on previous page.)

Fig. 2 Association between age and varicocele in the random-effects model of observational studies by the type of studydesign (a) and ethnicity (b); association between height and varicocele in the random-effects model of observational studies by the type of studydesign (c) and ethnicity (d); association between weight and varicocele in the random-effects model of observational studies by the type of studydesign (e) and ethnicity (f); association between body mass index (BMI) and varicocele in the random-effects model of observational studies by the type of studydesign (g) and ethnicity (h)

subgroup analysis by ethnicity indicated that patients with varicocele had a lower BMI than patients without varicocele in the Asian population (WMD $=-1.96,95 \%$ $\mathrm{CI}=-2.91$ to $-1.01, P<0.001)$ and Caucasian population (WMD $=-1.07,95 \% \mathrm{CI}=-1.49$ to $-0.65, \quad P<0.001$ ) (Fig. 2h and Table 2).

\section{BMI of patients with different grades of varicocele}

We performed a subgroup analysis to investigate the effect of BMI on the severity of varicocele. Patients with grades I, II, and III varicocele had a lower BMI than patients without varicocele, with WMDs of -1.85 (95\% CI: -3.68 to -0.02$),-2.88$ (95\% CI: -5.17 to -0.60$)$, and -
3.91 (95\% CI: -6.87 to -0.95 ), respectively (Fig. 3b). The grade of varicocele was inversely correlated with increased BMI. However, there was between-study heterogeneity that could not be ignored $\left(I^{2}=96.4 \%, P<0.001\right)$. Therefore, stratified analyses by study design and ethnicity were performed to explore the origin of the significant heterogeneity. In the subgroup analysis of study design, patients with grade I varicocele had a lower BMI than patients without varicocele in the case-control studies $(\mathrm{WMD}=-2.44,95 \% \mathrm{CI}=-4.19$ to $-0.70, P=$ 0.003) (Fig. 4a). Similarly, the subgroup analysis by ethnicity indicated that patients with grade I varicocele had a lower BMI than patients without varicocele in the

Table 2 Meta-analysis results of age, height, weight, and body mass index (BMI)

\begin{tabular}{|c|c|c|c|c|c|c|c|}
\hline \multirow[t]{2}{*}{ Outcomes } & \multirow[t]{2}{*}{$N$} & \multirow[t]{2}{*}{ Model used } & \multicolumn{2}{|c|}{ Heterogeneity } & \multicolumn{2}{|l|}{ Pooled WMD } & \multirow{2}{*}{$\begin{array}{l}\text { Begg's } \\
\text { test } P\end{array}$} \\
\hline & & & $\mathrm{I}^{2}(\%)$ & $P$ value & WMD (95 Cl) & $P$ value & \\
\hline \multicolumn{8}{|l|}{ Age } \\
\hline Case -control study & 9 & Random-effects & 98.1 & 0.000 & $-1.27(-4.55$ to 2.01$)$ & 0.448 & \\
\hline Cross-sectional study & 3 & Random-effects & 50.4 & 0.133 & $-0.01(-0.17$ to 0.15$)$ & 0.902 & \\
\hline Caucasian & 6 & Random-effects & 99.5 & 0.000 & $-1.22(-3.65$ to 1.21$)$ & 0.325 & \\
\hline Asian & 6 & Random-effects & 0.0 & 0.691 & $-0.07(-0.30$ to 0.16$)$ & 0.542 & \\
\hline Overall & 12 & Fixed-effects & 98.9 & 0.000 & $-0.93(-2.19$ to 0.33$)$ & 0.149 & 0.446 \\
\hline \multicolumn{8}{|l|}{ height } \\
\hline Case -control study & 5 & Random-effects & 54.4 & 0.067 & 2.19 (0.91 to 3.47$)$ & 0.001 & \\
\hline Cross-sectional study & 5 & Random-effects & 82.7 & 0.000 & 1.30 (0.96 to 1.63$)$ & 0.000 & \\
\hline Caucasian & 6 & Random-effects & 67.6 & 0.009 & 1.37 (0.94 to 1.79$)$ & 0.000 & \\
\hline Asian & 4 & Random-effects & 79.2 & 0.002 & 1.79 (0.75 to 2.82$)$ & 0.001 & \\
\hline Overall & 10 & Random-effects & 73.5 & 0.000 & 1.41 (1.07 to 1.74$)$ & 0.000 & 0.681 \\
\hline \multicolumn{8}{|l|}{ weight } \\
\hline Case -control study & 5 & Random-effects & 86.6 & 0.000 & $-0.63(-4.19$ to 2.93$)$ & 0.729 & \\
\hline Cross-sectional study & 2 & Random-effects & 97.8 & 0.000 & $2.08(-2.91$ to 7.08$)$ & 0.414 & \\
\hline Caucasian & 4 & Random-effects & 89.7 & 0.000 & $-0.05(-3.31$ to 3.20$)$ & 0.975 & \\
\hline Asian & 3 & Random-effects & 91.7 & 0.000 & $0.51(-4.36$ to 5.39$)$ & 0.837 & \\
\hline Overall & 7 & Random-effects & 92.2 & 0.000 & $0.24(-2.24$ to 2.72$)$ & 0.850 & 0.746 \\
\hline \multicolumn{8}{|l|}{ BMI } \\
\hline Case -control study & 11 & Random-effects & 94.3 & 0.000 & $-.1 .38(-2.06$ to -0.70$)$ & 0.000 & \\
\hline Cross-sectional study & 6 & Random-effects & 97.3 & 0.000 & $-1.29(-1.69$ to -0.89$)$ & 0.000 & \\
\hline Caucasian & 10 & Random-effects & 97.3 & 0.000 & $-1.07(-1.49$ to -0.65$)$ & 0.000 & \\
\hline Asian & 7 & Random-effects & 94.9 & 0.000 & $-1.96(-2.91$ to -1.01$)$ & 0.000 & \\
\hline Overall & 17 & Random-effects & 96.5 & 0.000 & $-1.35(-1.67$ to -1.03$)$ & 0.000 & 0.097 \\
\hline
\end{tabular}



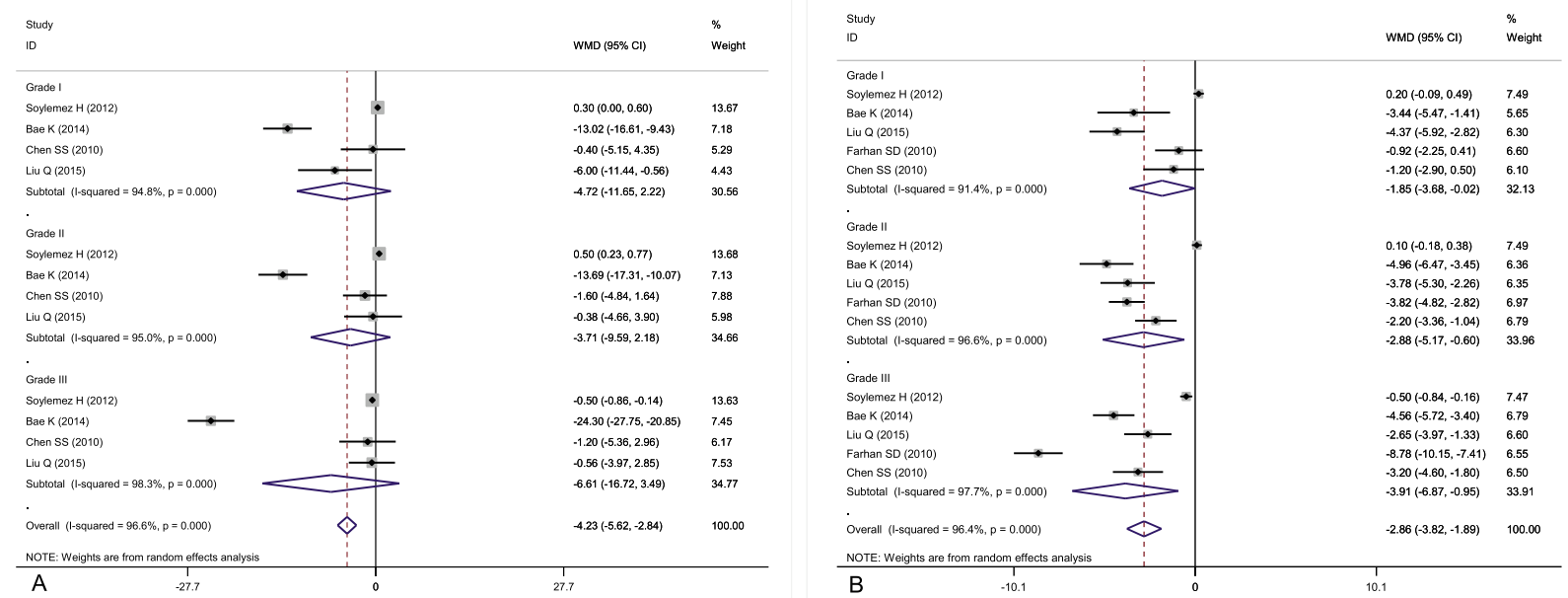

Fig. 3 a Forest plot of the association between age and severity of varicocele; $\mathbf{b}$ forest plot of the association between body mass index (BMI) and severity of varicocele

Asian population (WMD $=-2.44,95 \% \mathrm{CI}=-4.19$ to $0.70, P=0.003$ ) (Fig. $4 \mathrm{~b}$ ). In the subgroup analysis of study design, patients with grade II varicocele had a lower BMI than patients without varicocele in the casecontrol studies (WMD $=-3.63,95 \% \mathrm{CI}=-4.73$ to -2.53 , $P=0.031$ ) (Fig. 4c). Similarly, the subgroup analysis by ethnicity indicated that patients with grade II varicocele had a lower BMI than patients without varicocele in the Asian population (WMD $=-3.63,95 \% \mathrm{CI}=-4.73$ to 2.53, $P=0.031$ ) (Fig. $4 \mathrm{~d}$ ). In the subgroup analysis of study design, patients with grade III varicocele had a lower BMI than patients without varicocele in the casecontrol studies $(\mathrm{WMD}=-4.80,95 \% \mathrm{CI}=-7.41$ to -2.18 , $P<0.001$ ) (Fig. 4e). Similarly, the subgroup analysis by ethnicity indicated that patients with grade I varicocele had a lower BMI than patients without varicocele in the Asian population $(\mathrm{WMD}=-4.80,95 \% \mathrm{CI}=-7.41$ to 2.18, $P<0.001$ ) (Fig. 4f).

\section{Sensitivity analyses}

Sensitivity analysis was conducted by excluding each study to evaluate possible biases. Our results showed that the overall effects did not significantly change after excluding any one study, indicating that the meatanalysis results were stable and reliable (Fig. 5).

\section{Publication bias}

Begg's funnel plot and pseudo 95\% CIs are presented in Fig. 6. Egger's test did not show any publication bias for age $(P=0.446)$, height $(P=0.681)$, weight $(P=0.746)$, or BMI $(P=0.097)$.

\section{Discussion}

Varicocele, the most common cause of male infertility, can impair spermatogenesis. The exact mechanism of varicocele development has not been fully clarified, although the "nutcracker phenomenon" theory has been widely accepted. The "nutcracker phenomenon" refers to the compression of the left renal vein between the superior mesenteric artery and the abdominal aorta [37].

Some studies have reported that there are no significant differences in age between patients with and without varicocele [13, 18, 19, 21]. Prabakaran et al. [9] and Pallotti et al. [3] reported that the incidence of varicocele was positively correlated with age. Al-Ai et al. [20] reported that age was inversely associated with varicocele grade. In this meta-analysis, we found that age was not associated with the prevalence or severity of varicocele.

Some studies have reported that there are no significant differences in height between patients with and without varicocele $[13,21,22]$, whereas other studies have reported that patients with varicocele are significantly taller than patients without varicocele $[3,8-11$, 14, 19]. The pooled results demonstrated that patients with varicoceles were taller than patients without varicoceles. That is to say, shorter height protects against varicocele and is associated with a decreased incidence of varicocele. Tsao et al. [19] speculated that taller height may be related to increased hydrostatic pressure in the spermatic vein, which in turn overwhelms the valve mechanisms in the veins, resulting in the formation of varicocele. Stratified analyses were performed to explore the influence of study design and ethnicity. We found a taller height in patients with varicocele in both Asian 

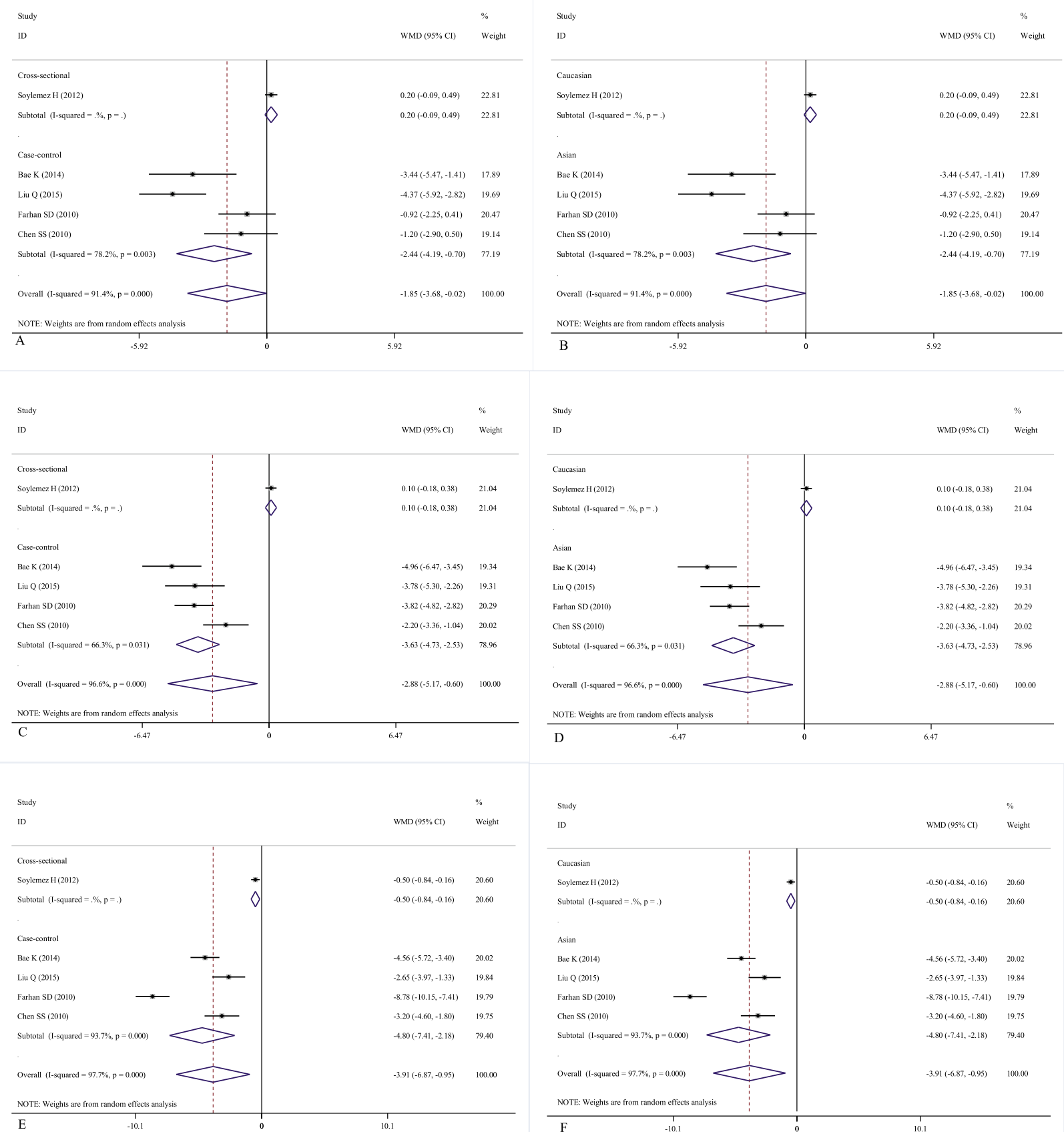

Fig. 4 Association between body mass index (BMI) and grade I varicocele in the random-effects model of observational studies by the type of study design (a) and ethnicity (b); association between body mass index (BMI) and grade II varicocele in the random-effects model of observational studies by the type of study design (c) and ethnicity (d); association between body mass index (BMI) and grade III varicocele in the random-effects model of observational studies by the type of study design (e) and ethnicity (f)

and Caucasian populations. We also found a taller height in patients with varicocele in both case-control study and cross-sectional study.

Some studies have reported that the weight of patients with varicocele is significantly heavier than that of those without varicocele [10, 11, 13, 14]. Kumanov et al. [15] and Tsao et al. [19] reported that the weight of patients with varicocele was significantly lighter than that of those without varicocele. Soylemez et al. [21] reported that there was no significant difference in weight 


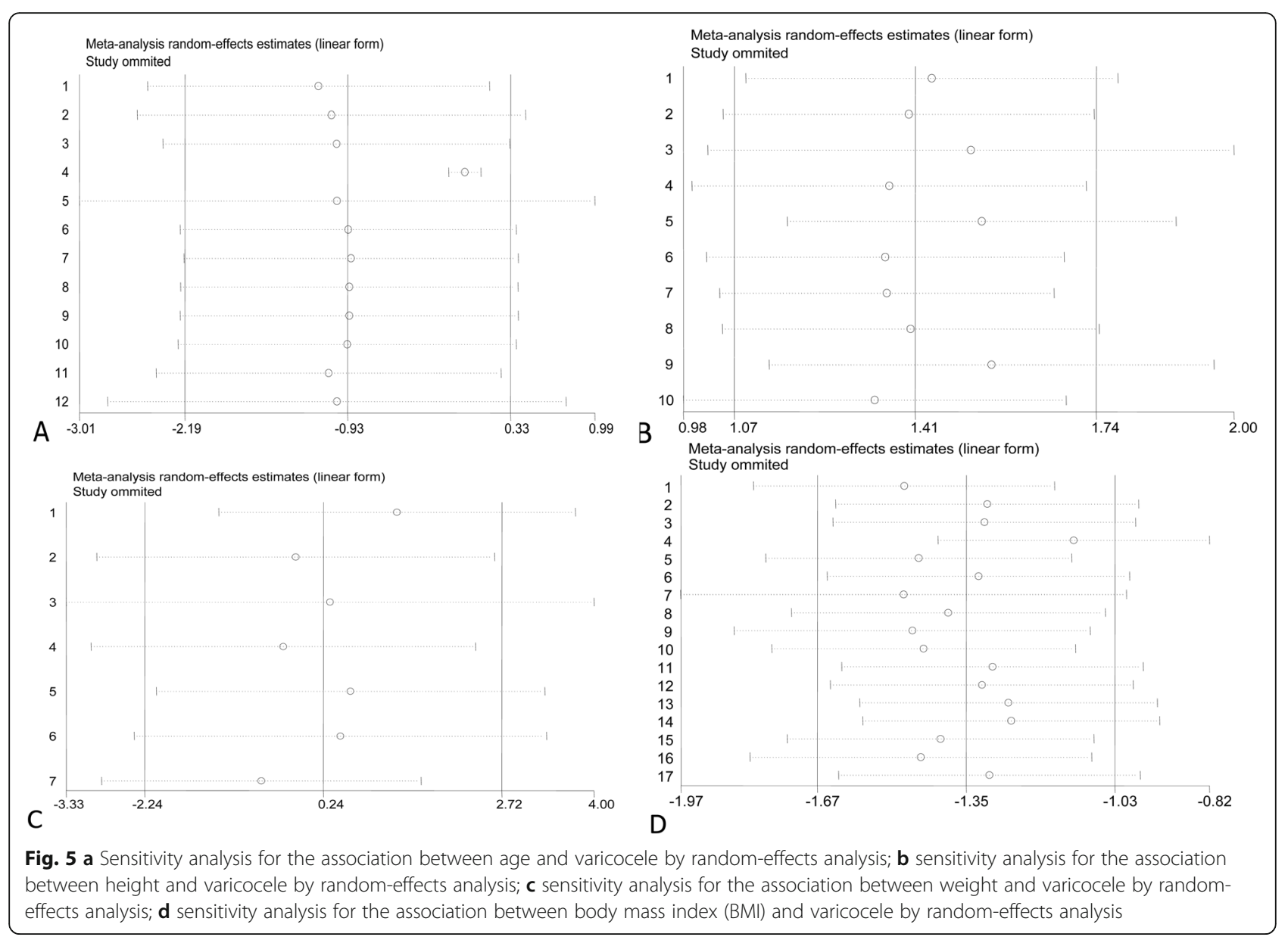

between patients with and without varicocele. In this meta-analysis, we found that weight was not associated with the incidence of varicocele.

Controversial findings on the association between BMI and varicocele have been reported in the literature. Some studies have reported that there is no significant differences in BMI between patients with and without varicocele [11, 13, 21], whereas other studies have reported that the prevalence of varicocele is inversely correlated with BMI $[3,8-10,12,15-20]$. In this study, the pooled results demonstrated that patients with varicocele had lower BMI than patients without varicocele. Thus, higher BMI protects against varicocele and is associated with a decreased incidence of varicocele. Our results support the "nutcracker phenomenon" theory. Subgroup analyses were performed to explore the influence of study design and ethnicity. We found a lower BMI in patients with varicocele in both Asian and Caucasian populations. We also found a lower BMI in patients with varicocele in both case-control and crosssectional studies. The association between BMI and the incidence of varicocele is due to a reduced nutcracker phenomenon in overweight and obese men.
Some studies [12, 21, 33, 35] have reported that BMI does not affect the severity of varicocele. Chen et al. [18] reported that patients with grade III varicocele had a lower BMI than patients with grade I and II varicocele, but the difference was not significant. Farhan et al. [27] reported that varicocele grade significantly decreased with increasing BMI. In this meta-analysis, we found that the grade of varicocele was inversely correlated with increased BMI.

There were three particular strengths of this systematic review and meta-analysis. First, 56,325 patients with varicocele and 1,334,694 patients without varicocele were included in the meta-analysis. Therefore, the sample size was large enough to draw a reliable conclusion. Second, we performed stratified analyses by study design and ethnicity. Third, we investigated the effect of age and BMI on the severity of varicocele.

There were two limitations to this meta-analysis. First, heterogeneity among studies still existed although we applied strict inclusion and exclusion criteria. Second, the number of included studies was small for some subgroups. 


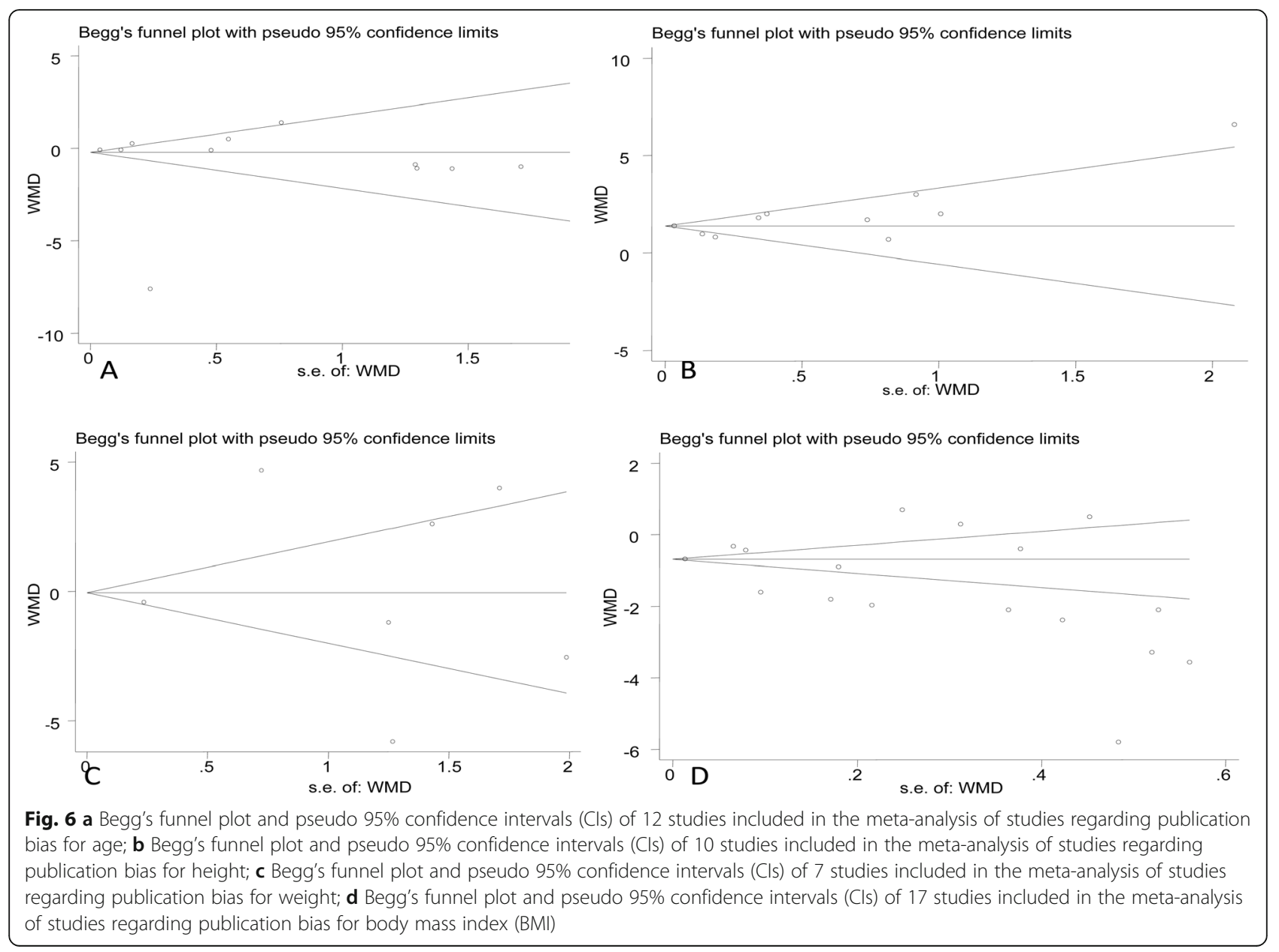

We found that the prevalence of varicocele was significantly associated with height and inversely correlated with BMI. The severity of varicocele was inversely correlated with increased BMI. Our results remind us of the necessity of early screening and treatment for varicocele in taller men and underweight men.

\section{Abbreviations}

BMI: Body mass index; CNKI: China National Knowledge Infrasturcture; WMDs: Weighted mean differences; Cls: Confidence intervals; SDs: Standard deviations

\section{Authors' contributions}

Conceived the idea: Runqing Li and Yushan Li. Conducted the literature search, study selection, and data extraction: Runqing Li, Junjie Liu, and Yushan Li. Interpreted the results: Runqing Li. Performed all the statistical analyses: Junjie Liu. Drafted and revised the manuscript: Runqing Li, Junjie Liu, Yushan Li, and Quanxian Wang. All authors approved the final version of the manuscript.

\section{Funding}

This work was supported by the Joint Construction Project of Henan Medical Science and Technology Research Plan (Grant No. LHGJ20190389).

\section{Availability of data and materials}

The datasets used during the current study are available from the corresponding author on reasonable request.

\section{Ethics approval and consent to participate}

This study was approved by the institutional ethics committee of the Third Affiliated Hospital of Zhengzhou University. Written informed consent was obtained from all participants before conducting the study.

\section{Consent for publication}

Not applicable.

\section{Competing interests}

The authors declare that they have no competing interests.

\section{Author details}

${ }^{1}$ The Neonatal Screening Center in Henan Province, The Third Affiliated Hospital of Zhengzhou University, Zhengzhou 450052, China. ${ }^{2}$ Henan Human Sperm Bank, The Third Affiliated Hospital of Zhengzhou University, No.7 Front Kangfu Street, Er'ai District, Zhengzhou 450052, People's Republic of China.

Received: 12 August 2020 Accepted: 8 January 2021

Published online: 20 January 2021

\section{References}

1. Wang YJ, Zhang RQ, Lin YJ, Zhang RG, Zhang WL. Relationship between varicocele and sperm DNA damage and the effect of varicocele repair: a meta-analysis. Reprod BioMed Online. 2012;25:307-14.

2. Ashok A, Reecha S, Avi H, Esteves SC. Effect of varicocele on semen characteristics according to the new 2010 World Health Organization criteria: a systematic review and meta-analysis. Asian J Androl. 2016;18:163-70 
3. Pallotti F, Paoli D, Carlini T, Vestri AR, Martino G, Lenzi A, et al. Varicocele and semen quality: a retrospective case-control study of 4230 patients from a single Centre. J Endocrinol Investig. 2017:41:1-8.

4. Shafi H, Esmaeilzadeh S, Delavar MA, Haydari FH, Mahdinejad N, Abedi S. Prevalence of Varicocele among primary and secondary infertile men: association with occupation, smoking and drinking alcohol. N Am J Med Sci. 2014;6:532-5.

5. Baazeem A, Belzile E, Ciampi A, Dohle G, Jarvi K, Salonia A, et al. Varicocele and male factor infertility treatment: a new meta-analysis and review of the role of varicocele repair. Eur Urol. 2011;60:796-808.

6. Said SA, Aribarg A, Virutamsen P, Chutivongse S, Koetsawang S, Meherjee P, et al. The influence of varicocele on parameters of fertility in a large group of men presenting to infertility clinics. Fertil Steril. 1992;57:1289-93.

7. Liu J, Zhang S, Liu M, Wang Q, Shen H, Zhang Y, et al. Prevalence of varicocoele and its association with body mass index among 39,559 rural men in eastern China: a population-based cross-sectional study. Andrology. 2017:5:562.

8. Gokce A, Demirtas A, Ozturk A, Sahin N, Ekmekcioglu O. Association of left varicocoele with height, body mass index and sperm counts in infertile men. Andrology. 2013;1:116-9.

9. Prabakaran S, Kumanov P, Tomova A, Hubaveshki S, Agarwal A. Adolescent Varicocele: association with Somatometric parameters. Urol Int. 2006;77:114-7.

10. May M, Taymoorian K, Beutner S, Helke C, Braun KP, Lein M, et al. Body size and weight as predisposing factors in varicocele. Scand J Urol Nephrol. 2006:40:45.

11. Delaney DP, Carr MC, Kolon TF, Snyder HM, Zderic SA. The physical characteristics of young males with varicocele. BJU Int. 2004;94:624-6.

12. Hassanzadeh K, Yavari-Kia P, Soleymanpour H, Ebrahimpour-Tolouei N, Alikhah $\mathrm{H}$. Effect of body mass index on severity and prevalence of varicocele. Pak J Biol Sci. 2011;14:869-75.

13. Kilic S, Aksoy Y, Sincer I, Erdil N, Yetkin E. Cardiovascular evaluation of young patients with varicocele. Fertil Steri. 2007;88:369-73.

14. Smith SM. Body size and weight in relation to varicocoele and hernia. Ann Hum Genet. 2015;21:304-12.

15. Kumanov P, Robeva RN, Tomova A. Adolescent Varicocele: Who Is at Risk? Pediatrics. 2008;121:e53-e7.

16. Handel LN, Shetty R, Sigman M. The relationship between Varicoceles and obesity - the journal of urology. J Urol. 2006;176:2138-40.

17. Nielsen ME, Stephen Z, Freedland SJ, Jarow JP. Insight on pathogenesis of varicoceles: relationship of varicocele and body mass index. Urology. 2006; 68:392-6.

18. Chen SS, Huang WJ. Differences in biochemical markers and body mass index between patients with and without Varicocele. J Chin Med Assoc. 2010;73:194-8.

19. Tsao C, Hsu C, Chou Y, Wu S, Sun G, Yu D, et al. The relationship between varicoceles and obesity in a young adult population. Int J Androl. 2009;32: 385-90.

20. Al-Ali BM, Marszalek M, Shamloul R, Pummer K, Trummer H. Clinical parameters and semen analysis in 716 Austrian patients with Varicocele. Urology. 2010;75:1069-73.

21. Söylemez H, Atar M, Sancaktutar AA, Bozkurt Y, Penbegül N. Varicocele among healthy young men in Turkey; prevalence and relationship with body mass index. Int Braz J Urol. 2012;38:116-21.

22. Stavropoulos NE, Mihailidis I, Hastazeris K, Moisidou R, Louka G, Filiadis I, et al. Varicocele in schoolboys. Arch Androl. 2002;48:187-92.

23. Baek M, Park SW, Moon KH, Chang YS, Jeong HJ, Lee SW, et al. Nationwide survey to evaluate the prevalence of varicoceles in south Korean middle school boys: a population based study. Int J Urol. 2011;18:55-60.

24. Moher D, Liberati A, Tetzlaff J, Altman DG, PRISMA Group. Preferred reporting items for systematic reviews and meta-analyses: the PRISMA statement. BMJ. 2009;339:b2535.

25. Stang A. Critical evaluation of the Newcastle-Ottawa scale for the assessment of the quality of nonrandomized studies in meta-analyses. Eur J Epidemiol. 2010;25:603-5.

26. Rostom A, Dubé C, Cranney A, Saloojee N, Sy R, Garritty C, et al. Celiac disease. US: Evid Rep Technol Assess (Summ); 2004

27. Farhan $\mathrm{S}$. The relation ship between Varicocele and body mass index. J Fact Med Baghdad. 2010;52:27-9.

28. Chanc Walters R, Marguet CG, Crain DS. Lower prevalence of Varicoceles in obese patients found on routine scrotal ultrasound. J Urol. 2012;187:599-601.
29. Yigitler C, Yanardag H, Silit E, Alpay AS. Evaluation of inguinoscrotal pathologies among adolescents with special emphasis on association between varicocele and body mass index. Urol J. 2012;9:592-9.

30. Özcelik F, Sen B. Comparison of body mass index and fat ratios between normal population and young adults with varicocele. Anatol J Clin Invest. 2013;7:41-5.

31. Rais A, Zarka S, Derazne E, Tzur D, Calderon-Margalit R, Davidovitch N, et al. Varicocoele among 1300000 Israeli adolescent males: time trends and association with body mass index. Andrology. 2013;1:663-9.

32. Doğantekin E, Görgel SN, Şahin E, Girgin C. Relationship between varicocele and anthropometric indices in infertile population. Dicle Med J. 2014:41:5963.

33. Bae K, Shin HS, Jung HJ, Kang SH, Jin BS, Park JS. Adolescent varicocele: are somatometric parameters a cause? Korean J Urol. 2014;55:533-5.

34. Gorur S, Candan Y, Helli A, Akcin S, Cekirge S, Kaya Y, et al. Low body mass index might be a predisposing factor for varicocele recurrence: a prospective study. Andrologia. 2015;47:448-54.

35. Liu Q, Zhang T, Zhu B, Fang Z, Liao Z, Wu W. Association between varicocele and body type. J Modern Urol. 2015;20:241-3.

36. Shafi $\mathrm{H}$, Agajani DM. Differences in body mass index and height factors between men with and without varicocele. Med Glas. 2015;12:212-5.

37. Coolsaet BL. The varicocele syndrome: venography determining the optimal level for surgical management. J Urol. 1980;124:833-9.

\section{Publisher's Note}

Springer Nature remains neutral with regard to jurisdictional claims in published maps and institutional affiliations.
Ready to submit your research? Choose BMC and benefit from:

- fast, convenient online submission

- thorough peer review by experienced researchers in your field

- rapid publication on acceptance

- support for research data, including large and complex data types

- gold Open Access which fosters wider collaboration and increased citations

- maximum visibility for your research: over $100 \mathrm{M}$ website views per year

At $\mathrm{BMC}$, research is always in progress.

Learn more biomedcentral.com/submissions 